\title{
Ectopic Prostate Tissue in the Cervix
}

National Cancer Institute

\section{Source}

National Cancer Institute. Ectopic Prostate Tissue in the Cervix. NCI Thesaurus. Code C127938.

Replacement of the endocervical epithelium with benign-appearing prostatic glands. 